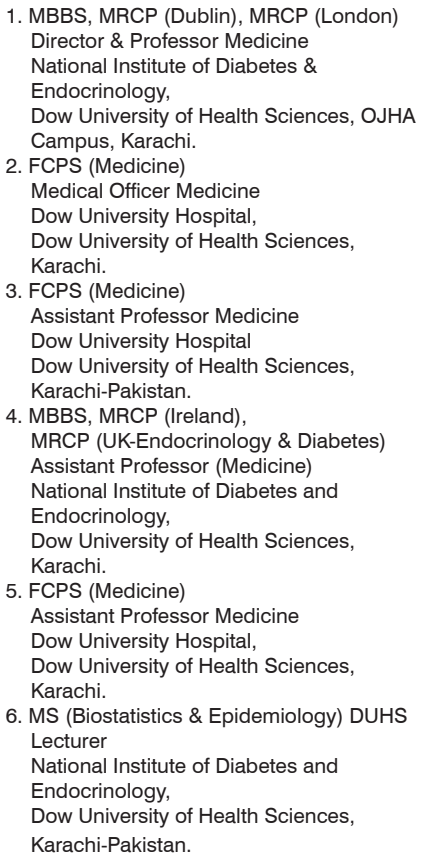

Correspondence Address:

Prof. Dr. Akhtar Ali Baloch

Department of Medicine

National Institute of Diabetes \&

Endocrinology,

Dow University of Health Sciences,

OJHA Campus, Karachi.

nide@duhs.edu.pk

Article received on:

18/08/2020

Accepted for publication:

$21 / 10 / 2020$

\section{Frequency and pattern of dyslipidemia in diabetes mellitus type 2.}

\begin{abstract}
Akhtar Ali', Rabeel Nawaz ${ }^{2}$, Faiza Dildar Ghuman ${ }^{3}$, Syed Muhammad Hasan ${ }^{4}$, Sadia Iqbal $^{5}$, Syed Muhammad Adnan 6
ABSTRACT... Objective: This study was designed to evaluate the frequency and pattern of dyslipidemia in patients of diabetes mellitus type 2. Study Design: Cross Sectional Observational study. Setting: Medicine Department and National Institute of Diabetes and Endocrinology OPD of Dow University Hospital OJHA Campus Karachi Sindh. Period: March 2018 to September 2018. Material \& Methods: 142 diabetes mellitus type 2 patients aged between $35-60$ years, selected by non-probability consecutive sampling method. Detailed medical history and blood sample for fasting lipid profile was obtained from each diabetic patient. Result: Out of 142 diabetic patients investigated for dyslipidemia, $72(50.7 \%)$ were male and $70(49.3 \%)$ were female with a mean age of $47.49 \pm 6.40$ (35-60) years. Dyslipidemia was detected in $114(80.3 \%)$ patients; with most common abnormality was elevated serum triglycerides $(54.9 \%)$, followed by decreased serum HDL cholesterol (50.7\%), elevated serum VLDL cholesterol (50.0\%), elevated serum cholesterol (38.7\%) and elevated serum LDL cholesterol (16.9\%). Conclusion: It was concluded that diabetes mellitus type 2 is directly correlated with higher incidence of dyslipidemia.
\end{abstract}

Key words: $\quad$ Cardiovascular Diseases, Dyslipidemia, Diabetes Mellitus, Mortality.

Article Citation: Ali A, Nawaz R, Ghuman FD, Hasan SM, Iqbal S, Adnan SM. Frequency and pattern of dyslipidemia in diabetes mellitus type 2. Professional Med $\mathrm{J}$ 2021; 28(6):828-832. https://doi.org/10.29309/TPMJ/2021.28.06.6080

\section{INTRODUCTION}

Diabetes mellitus type 2 is one of the heterogenous metabolic disorders, affecting the population worldwide. ${ }^{1}$ It is characterized with abnormal functioning of carbohydrate, protein and lipid metabolism, resulting in hyperglycemia and impaired insulin secretion or resistance or both. ${ }^{2}$ The actual pathogenesis of diabetes mellitus type 2 is still unknown, but it is being proposed that some genetic, and behavioral factors along with environmental risk factors, such as physical inactivity and obesity are important and play their role in development of diabetes. ${ }^{1-3}$

Globally diabetes mellitus type 2 included in essential and leading causes of mortality and disability. ${ }^{4}$ In last thirty years DM spreads epidemically and becomes $9^{\text {th }}$ major cause of mortality. Globally one in eleven adults is diabetic and $90 \%$ of them are type 2 diabetic. ${ }^{5}$ According to International diabetic federation (IDF), 425 million adults are diabetic, among which two-third (327 million) are in working age, whereas 212 million are undiagnosed diabetic. ${ }^{6}$ Prevalence of diabetes mellitus type 2 is progressively increasing and affecting developing countries more as compared to developed countries. ${ }^{7}$ Diabetes mellitus type 2 is rapidly emerging in Asian countries, among them China, India and Pakistan are at the top. In Pakistan diabetes mellitus type 2 prevalence is $11.77 \% ., 5$

Diabetes mellitus type 2 is directly related with higher risk of cardiovascular diseases (CVD) that increased the mortality rate as compared to nondiabetics. Dyslipidemia is among well accredited 
risk factors of diabetes that enhanced the cardiovascular problems. ${ }^{9}$ Diabetic dyslipidemia is also known as atherogenic dyslipidemia. High plasma triglyceride concentration, small dense low-density lipoprotein (sdLDL) cholesterol and very low-density lipoprotein (VLDL) and decreased high density lipoprotein (HDL) are the distinctive characteristics of diabetic dyslipidemia. ${ }^{10}$ Dyslipidemia is more frequent with diabetes and it worsens with poor hyperglycemia management. Thus, appropriate investigation of lipid profile in diabetic patients is very necessary that will be helpful in early diagnosis, management and treatment of diabetic complications. ${ }^{11}$ This study was designed to evaluate the prevalence and pattern of dyslipidemia in patients of diabetes mellitus type 2 .

\section{MATERIAL \& METHODS}

It was a cross-sectional, observational study conduct at Medicine department and National Institute of Diabetes and Endocrinology OPD at Dow University Hospital Ojha campus Karachi Sindh. Among type 2 diabetic patients of either gender aged between 35-60 years 142 were selected by non-probability consecutive sampling technique. Patients on dialysis, taking lipid lowering medicines, having acute complications (such as diabetic keto-acidosis and hyperglycemic hyperosmolar non-ketotic coma) or hypothyroidism, nephrotic syndrome, diabetes mellitus type 1, lactic-acidosis and hypoglycemia were excluded. Informed consent was obtained from selected diabetic patients and detailed medical history including body mass index (BMI), smoking status and about hypertension was obtained. Blood samples of each patient was collected in aseptic condition and sent to clinical laboratory for fasting lipid profile.

Data was analyzed on Statistical Package for Social Science (SPSS) software, Version 22. Mean and standard deviation was computed for age, serum cholesterol, serum triglycerides, HDL cholesterol, LDL cholesterol and VLDL cholesterol. Frequency of age, gender, BMI, hypertension and smoking was obtained and also stratified with dyslipidemia by using Chi square test $(P$ value $\leq 0.05)$. Bivariate correlation was performed between serum lipid profile variables.

\section{OPERATIONAL DEFINITION}

\section{Diabetes Mellitus Type 2}

Patient having plasma fasting glucose level $\geq$ $126 \mathrm{mg} / \mathrm{dl}$ or taking diabetic drugs.

\section{Dyslipidemia}

Patient having one or more following abnormalities; Serum cholesterol: $\geq 200 \mathrm{mg} /$ dl, Serum triglycerides: $\geq 150 \mathrm{mg} / \mathrm{dl}$, HDL cholesterol: $\leq 40 \mathrm{mg} / \mathrm{dl}$, LDL cholesterol: $\geq 160$ $\mathrm{mg} / \mathrm{dl}$ and VLDL cholesterol: $\geq 30 \mathrm{mg} / \mathrm{dl}$.

\section{Smoker}

Patient taking 10 cigarettes/day for more than one year.

\section{Hypertension}

Patient having systolic blood pressure greater than $140 \mathrm{mmHg}$ or on anti-hypertensive drugs.

\section{RESULTS}

During this study, 142 diabetic patients were investigated for lipid profile, out of which 72 (50.7\%) patients were male and 70 (49.3\%) were female. Mean and standard deviation of age was $47.49 \pm 6.40(35-60)$ years, categorized into three age group; 35-40, 41-50 and 51-60 years having 38 (26.8\%), 61 (43.0\%) and $43(30.3 \%)$ patients respectively. In observed diabetic patients 26 (18.3\%) and 53 (37.3\%) patients have history of smoking and hypertension respectively. BMI of diabetic patients was normal in 22 (15.5\%), overweight in 64 (45.1\%) and obese in 56 (39.4\%) patients (Table-I).

Lipid profile of diabetic patients were performed and analyzed, results shows serum cholesterol, serum triglycerides, HDL cholesterol, LDL cholesterol and VLDL cholesterol level were normal in 87 (61.3\%), 64 (45.1\%), 70 (49.3\%), 118 (83.1\%) and 71 (50\%) patients and abnormal in 55 (38.7\%), 78 (54.9\%), 72 (50.7\%), 24 (16.9\%) and 71 (50\%) patients respectively (Table-II). On the basis of lipid profile dyslipidemia was present in 114 (80.3\%) diabetic patients and absent in 28 
(19.7\%) diabetic patients.

Dyslipidemia in diabetic patients was evaluated with different risk factors such as gender, age, smoking, hypertension and BMI. Gender and smoking shows non-significant relation whereas age, BMI and hypertension shows significant relation with dyslipidemia in diabetes mellitus type 2 patients (Table-III).

In correlating investigation of lipid profile in diabetic patients, serum cholesterol shows highly significant relation with serum triglycerides, LDL cholesterol and VLDL cholesterol. Serum triglycerides shows significant relation with serum cholesterol and HDL cholesterol. HDL cholesterol shows significant relation with serum triglycerides. LDL cholesterol shows significant relation with serum cholesterol and VLDL cholesterol, whereas

VLDL cholesterol shows significant relation with serum cholesterol and LDL cholesterol (Table-IV).

\begin{tabular}{|l|c|}
\hline \multicolumn{1}{|c|}{ Variable } & Frequency (N) \% \\
\hline $\begin{array}{l}\text { Gender } \\
\text { Male } \\
\text { Female }\end{array}$ & $72(50.7)$ \\
\hline Age (years) & $70(49.3)$ \\
$35-40$ & \\
$41-50$ & $38(26.8)$ \\
$51-60$ & $61(43.0)$ \\
\hline Mean \pm SD & $43(30.3)$ \\
\hline Smoker & $47.49 \pm 6.40$ \\
\hline Hypertension & $26(18.3)$ \\
\hline BMI & $53(37.3)$ \\
Normal & \\
Overweight & $22(15.5)$ \\
Obese & $64(45.1)$ \\
\hline & $56(39.4)$ \\
\hline
\end{tabular}

\begin{tabular}{|l|c|c|c|}
\hline \multicolumn{1}{|c|}{ Variable } & Mean \pm SD & Normal N (\%) & Abnormal N (\%) \\
\hline Serum Cholesterol & $196.68 \pm 39.28$ & $87(61.3)$ & $55(38.7)$ \\
\hline Serum Triglycerides & $194.88 \pm 127.62$ & $64(45.1)$ & $78(54.9)$ \\
\hline HDL Cholesterol & $37.49 \pm 6.43$ & $70(49.3)$ & $72(50.7)$ \\
\hline LDL Cholesterol & $130.29 \pm 32.69$ & $118(83.1)$ & $24(16.9)$ \\
\hline VLDL Cholesterol & $36.33 \pm 28.08$ & $71(50)$ & $71(50)$ \\
\hline
\end{tabular}

\begin{tabular}{|c|c|c|c|c|}
\hline \multirow[b]{2}{*}{ Variable } & \multicolumn{2}{|c|}{ Dyslipidemia } & \multirow[b]{2}{*}{ Total } & \multirow[b]{2}{*}{ P-Value } \\
\hline & $\begin{array}{c}\text { Present } \\
\text { N (\%) }\end{array}$ & $\begin{array}{c}\text { Absent } \\
\text { N (\%) }\end{array}$ & & \\
\hline $\begin{array}{l}\text { Gender } \\
\text { Male } \\
\text { Female }\end{array}$ & $\begin{array}{l}56(39.4) \\
58(40.8)\end{array}$ & $\begin{array}{c}16(11.3) \\
12(8.5)\end{array}$ & $\begin{array}{l}72(50.7) \\
70(49.3)\end{array}$ & 0.447 \\
\hline $\begin{array}{l}\text { Age (years) } \\
35-40 \\
41-50 \\
51-60\end{array}$ & $\begin{array}{l}37(26.1) \\
47(33.1) \\
30(21.1)\end{array}$ & $\begin{array}{c}1(0.7) \\
14(9.9) \\
13(9.2)\end{array}$ & $\begin{array}{l}38(26.8) \\
61(43.0) \\
43(30.3)\end{array}$ & 0.005 \\
\hline Smoker & $20(14.1)$ & $6(4.2)$ & 26 (18.3) & 0.634 \\
\hline Hypertension & $35(24.6)$ & $18(12.7)$ & $53(37.3)$ & 0.001 \\
\hline $\begin{array}{l}\text { BMI } \\
\text { Normal } \\
\text { Overweight } \\
\text { Obese }\end{array}$ & $\begin{array}{c}11(7.7) \\
59(41.5) \\
44(31.0)\end{array}$ & $\begin{array}{c}11(7.7) \\
5(3.5) \\
12(8.5)\end{array}$ & $\begin{array}{l}22(15.5) \\
64(45.1) \\
56(39.4)\end{array}$ & 0.001 \\
\hline
\end{tabular}




\begin{tabular}{|c|c|c|c|c|c|}
\hline Variable & $\begin{array}{c}\text { Serum } \\
\text { Cholesterol }\end{array}$ & $\begin{array}{c}\text { Serum } \\
\text { Triglycerides }\end{array}$ & $\begin{array}{c}\text { HDL } \\
\text { Cholesterol }\end{array}$ & $\begin{array}{c}\text { LDL } \\
\text { Cholesterol }\end{array}$ & $\begin{array}{c}\text { VLDL } \\
\text { Cholesterol }\end{array}$ \\
\hline Serum Cholesterol & & 0.001 & 0.0579 & 0.001 & 0.001 \\
\hline HDL Cholesterol & 0.59 & 0.018 & & 0.919 & 0.271 \\
\hline LDL Cholesterol & 0.001 & 0.873 & 0.919 & & 0.002 \\
\hline
\end{tabular}

\section{DISCUSSION}

Diabetes mellitus type 2 is a chronic disorder, responsible for increased risk of cardiovascular diseases (CVD) that counts $75 \%$ deaths in diabetic patients. ${ }^{12}$ Lipid abnormalities are very common in diabetes mellitus type 2 patients along with other risk factors such smoking, hypertension and obesity. ${ }^{13}$ The main focus of current study was on the determination of the frequency of dyslipidemia in diabetic patients (type 2) visiting Dow University Hospital Karachi.

In this study, dyslipidemia was detected in $80.3 \%$ diabetes mellitus type 2 patients, along with most common lipid profile abnormality was elevated serum triglycerides (54.9\%), followed by decreased serum HDL cholesterol (50.7\%), elevated serum VLDL cholesterol (50.0\%), elevated serum cholesterol (38.7\%), and elevated serum LDL cholesterol in (16.9\%) diabetic patients. Similar results were reported by different researcher such as Dhoj TS, et al. ${ }^{9}$, Joshi KR, et al. ${ }^{11}$, and Goel S, et al. ${ }^{14}$

Different studies reported decrease in HDL cholesterol level as an indicator for premature coronary heart diseases (CHD). During diabetes $\mathrm{HDL}$ cholesterol is converted into VLDL cholesterol and denser LDL cholesterol results in decrease HDL cholesterol level. HDL cholesterol is also rapidly converted into smaller particles by hepatic lipase and removed from the plasma. Appropriate treatment and management of blood glucose level raises and maintain the HDL cholesterol level in plasma, hence justifying the role of improper blood glucose management as culprit in increasing lipid abnormalities..$^{9,14-15}$

In this study, other risk factors in diabetes mellitus type 2 patients were also investigated such as smokers were $18.3 \%$ and hypertensive were $37.3 \%$ patients, however rate of smoking was low in this study and shows non-significant relation with dyslipidemia, whereas hypertension shows highly significant relation with dyslipidemia. A similar type of study performed by Goel S, et al., on dyslipidemia in diabetes mellitus type 2 patients' reports the hypertension in $66 \%$ and smoking in only $6 \%$ patients. ${ }^{14}$

Another important risk factor is BMI that was elevated in $84.5 \%$ patients [ $45.1 \%$ overweight and $39.4 \%$ obese] and normal in only $15.5 \%$ patients. A study by Dhoj TS, et al., reports that $50 \%$ patients had normal BMI, $28.0 \%$ overweight and $22.0 \%$ obese. $^{9}$ In this study frequency of dyslipidemia was higher in overweight and obese patients as compared to normal BMI patients.

Different researchers reported that high level of serum triglycerides (hypertriglyceridemia) is directly correlated with improper treatment and management of diabetes mellitus and obesity. Similarly, proper management and control on blood glucose level decreases the level of serum triglycerides.9,14-15 Dyslipidemia reported more often with diabetes mellitus type 2 and frequent abnormality in lipid profile is hypertriglyceridemia and decreased HDL cholesterol level, heighten the risks of development of CVD that results in premature death of diabetic patients. Therefore, appropriate treatment and management of diabetes mellitus type 2 is very important along with early investigation, diagnosis and treatment of dyslipidemia.

\section{CONCLUSION}

It was concluded that diabetes mellitus type 2 
is directly correlated with higher incidence of dyslipidemia with elevated serum cholesterol, serum triglycerides, serum LDL cholesterol, serum VLDL cholesterol and decreased serum HDL cholesterol.

Copyright $\Subset 21$ Oct, 2020.

\section{REFERENCES}

1. Ahmed N, Khan J, Siddiqui TS. Frequency of dyslipidaemia in type 2 diabetes mellitus in patients of Hazara division. J Ayub Med Coll Abottabad. 2008; 20(2):51-4.

2. DeFronzo RA, Ferrannini E, Groop L, Henry RR, Herman WH, Holst JJ, et al. Type 2 diabetes mellitus. Nat Rev Dis Primers. 2015 Jul 23; 1:15019.

3. American Diabetes Association. 5. Prevention or delay of type 2 diabetes: Standards of medical care in diabetes-2018. Diabetes care. 2018 Jan 1; 41(Suppl 1):S51-4

4. Stewart GL, Tambascia M, Guzman JR, Etchegoyen F, Carrion JO, Artemenko S. Control of type 2 diabetes mellitus among general practitioners in private practice in nine countries of Latin America. Pan Am J Public Health. 2007; 22(1):12-20.

5. Zheng Y, Ley SH, Hu FB. Global aetiology and epidemiology of type 2 diabetes mellitus and its complications. Nat Rev Endocrinol. 2018 Feb; 14(2):8898.

6. International Diabetic Federation. IDF Diabetes Atlas, 8th edn. Brussels, Belgium: International diabetes federation, 2017. [cited 10 October 2018]. Available from: http://diabetesatlas.org/IDF_Diabetes_Atlas_8e_ interactive EN/.
7. Kaiser $A B$, Zhang $N$, Van Der Pluijm W. Global prevalence of type 2 diabetes over the next ten years (2018-2028). Diabetes. 2018; 67(Suppl 1):202-LB.

8. Meo SA, Zia I, Bukhari IA, Arain SA. Type 2 diabetes mellitus in Pakistan: Current prevalence and future forecast. J Pak Med Assoc. 2016 Dec; 66(12):1637-42.

9. Dhoj TS, Raj KCS, Santosh G, Deepika G. Dyslipidemia in type 2 diabetes mellitus. J Pathol Nepal. 2017; 7(2):1149-54.

10. Schofiled JD, Liu Y, Rao-Balakrishna P, Malik RA, Soran H. Diabetes dyslipidemia. Diabetes Ther. 2016 Jun; 7(2):203-19.

11. Joshi KR, Bhattacharya K, Kar SK, Yadav PK, Sah SK, Pokhrel S. Correlation of type 2 diabetes mellitus and dyslipidemia among Nepalese. Asian J Pharm Clin Res. 2014; 7(5):295-9.

12. Naito R, Miyauchi K. Coronary artery disease and type 2 diabetes mellitus. Int Heart J. 2017 Aug 3; 58(4):47580.

13. Palazhy S, Viswanathan V. Lipid abnormalities in type 2 diabetes mellitus patients with overt nephropathy. Diabetes Metab J. 2017 Apr; 41(2):128-34.

14. Goel S, Garg PK, Malhotra V, Madan J, Mitra SK, Grover $\mathrm{S}$. Dyslipidemia in type II diabetes mellitus - an assessment of the main lipoprotein abnormalities. Bangladesh J Med Sci. 2016; 15(1):99-102.

15. Mooradian AD. Dyslipidemia in type 2 diabetes mellitus. Nat Clin Pract Endocrinol Metab. 2009 Mar; 5(3):150-9.

\begin{tabular}{|c|l|l|l|}
\hline \multicolumn{3}{|c|}{ AUTHORSHIP AND CONTRIBUTION DECLARATION } \\
\hline Sr. \# & \multicolumn{1}{|c|}{ Author(s) Full Name } & \multicolumn{1}{|c|}{ Contribution to the paper } & Author(s) Signature \\
\hline 1 & Akhtar Ali & $\begin{array}{l}\text { Topic selection and literature } \\
\text { review. } \\
\text { Writing of introduction. }\end{array}$ \\
\hline 3 & Rabeel Nawaz & Faiza Dildar Ghuman & Abstract writing. \\
4 & Syed Muhammad Hasan & Data collection & \\
5 & Sadia lqbal & Discussion writing. \\
6 & Syed Muhammad Adnan & Data analysis. \\
\hline
\end{tabular}

